\title{
Taxation and the sustainability of collusion: ad valorem versus specific taxes
}

\author{
Helmuts Azacis ${ }^{1} \cdot$ David R Collie $^{1}$ (D)
}

Received: 7 November 2016 / Accepted: 13 November 2017 / Published online: 24 November 2017

C The Author(s) 2017. This article is an open access publication

\begin{abstract}
Assuming constant marginal cost, it is shown that a switch from specific to ad valorem taxation that results in the same collusive price has no effect on the critical discount factor required to sustain collusion. This result is shown to hold for Cournot oligopoly when collusion is sustained with Nash-reversion strategies or optimal-punishment strategies. In a Cournot duopoly model with linear demand and quadratic costs, it is shown that the critical discount factor is lower with an ad valorem tax than with a specific tax that results in the same collusive price. However, in contrast to Colombo and Labrecciosa (J Public Econ 97:196-205, 2013) it is shown that the revenue is always higher with an ad valorem tax than with a specific tax.
\end{abstract}

Keywords Taxes $\cdot$ Imperfect competition $\cdot$ Oligopoly $\cdot$ Cartel $\cdot$ Supergame

JEL Classification H21 $\cdot \mathrm{H} 22 \cdot \mathrm{L} 13 \cdot \mathrm{L} 41 \cdot \mathrm{C} 72 \cdot \mathrm{C} 73$

\section{Introduction}

An ad valorem tax and specific tax that result in the same consumer price will yield the same tax revenue under perfect competition, but an ad valorem tax will yield higher tax revenue than a specific tax under monopoly. ${ }^{1}$ An early analysis of taxes under Cournot oligopoly with homogeneous products is provided by Dierickx et al. (1988), but the

\footnotetext{
1 See Keen (1998) for a non-technical introduction to the topic and details of the earlier literature starting with Cournot in 1838, Wicksell in 1896 and Suits and Musgrave (1953).

$凶 \quad$ David R Collie

Collie@cardiff.ac.uk

1 Cardiff Business School, Cardiff University, Aberconway Building, Cardiff CF10 3EU, United Kingdom
} 
systematic comparison of ad valorem and specific taxes under oligopoly began with the article by Delipalla and Keen (1992). In a conjectural variation oligopoly model they demonstrate that an ad valorem tax is superior to a specific tax by considering a tax reform that reduces the specific tax and increases the ad valorem tax in such a way that the first-round effect on tax revenue, at the initial equilibrium price, is zero (denoted as a $P$-shift). Skeath and Trandel (1994a) demonstrate that a specific tax can be replaced by a Pareto superior ad valorem tax under monopoly that yields higher consumer surplus, profits and tax revenue, and under oligopoly if the tax rate is sufficiently high. ${ }^{2}$

Assuming identical and constant marginal cost, Anderson et al. (2001) demonstrate that an ad valorem tax will yield higher tax revenue than a specific tax that results in the same consumer price. They also consider Cournot and Bertrand oligopoly with a fixed number of firms and asymmetric costs, and free entry with symmetric costs. Wang and Zhao (2009) show that specific taxation can be superior to ad valorem taxation with differentiated products and asymmetric costs under Cournot and Bertrand oligopoly. Recently, in a model with endogenous market structure Vetter (2017) shows that a specific tax may be superior to an ad valorem tax. In a strategic market game model of oligopoly, Grazzini (2006) shows that specific taxation can be superior to ad valorem taxation, but this result is driven by the social welfare function. Schröder (2004) shows that ad valorem taxation is superior to specific taxation under monopolistic competition with Dixit-Stiglitz preferences, but Vetter (2013) argues that the result is due to the functional form rather than the mode of competition.

Recently, Colombo and Labrecciosa (2013) compared the sustainability of collusion with ad valorem and specific taxation under Cournot and Bertrand oligopoly using the $P$-shift employed by Delipalla and Keen (1992). They consider infinitely-repeated supergames where collusion is sustained by either Nash-reversion or optimal punishment strategies, and show that a shift from specific to ad valorem taxation makes it easier for firms to sustain collusion. Consequently, in contrast to conventional wisdom, they demonstrate that the specific tax may yield higher tax revenue than an advalorem tax when collusion is sustainable with the ad valorem tax but is not sustainable with the specific tax. In this comparison of tax revenue, they assume that there is full collusion with the ad valorem tax but no collusion with the specific tax.

In this paper, the sustainability of collusion with ad valorem and specific taxes will be reconsidered using a different approach. Rather than using the $P$-shift, the assumption of constant marginal cost will be used as in Anderson et al. (2001) so that it is possible to find a specific tax that results in the same consumer price as an ad valorem tax in each phase of the supergame with general demand functions under Cournot oligopoly. In contrast to Colombo and Labrecciosa (2013), it will be shown that the critical discount factor required to sustain collusion using Nash-reversion strategies or optimal-punishment strategies is the same with an ad valorem tax as with a specific tax that results in the same price. Using particular functional forms, linear demand and quadratic costs, it will be shown that it is easier to sustain collusion with an ad valorem tax than with a specific tax that results in the same price when

2 The topic has also been addressed for tariffs in the international trade literature, see Kowalczyk and Skeath (1994), Skeath and Trandel (1994b). 
marginal cost is increasing. However, in contrast to Colombo and Labrecciosa (2013), it is shown that an ad valorem tax always yields higher revenue than a specific tax when the possibility of partial collusion is considered.

\section{Cournot oligopoly}

Consider an infinitely-repeated Cournot oligopoly where firms produce a homogeneous product, and the firms have identical and constant marginal cost. There are two or more firms, $n \geq 2$, in the industry. All firms have the same cost function: $c\left(q_{i}\right)=\kappa q_{i}$, where $q_{i}$ is the output of the $i$ th firm and its marginal cost is $c^{\prime}\left(q_{i}\right)=\kappa>0$, which is constant. ${ }^{3}$ The inverse demand function is: $P=P(Q)$, where $P$ is the consumer price and $Q=\sum_{j=1}^{n} q_{j}$ is the total output of the firms, and it is assumed to be downward sloping so $P^{\prime}(Q)<0$. Since this is a symmetric Cournot oligopoly, the existence of equilibrium is implied by the results of McManus (1964, 1962). To ensure the uniqueness (and stability) of the Cournot equilibrium, it will be assumed that $(n+1) P^{\prime}+Q P^{\prime \prime}<0$, see Kolstad and Mathiesen (1987). The government imposes either an ad valorem consumption tax: $\tau$ (expressed as a proportion of the producer price), or a specific (per unit) consumption tax: $t$ at the beginning of the game (stage zero), where $\tau \geq 0$ and $t \geq 0 .{ }^{4}$ The comparison of the effects of the two forms of taxation will be achieved by comparing an ad valorem tax with a specific tax that results in the same price in all phases of the game. As in Anderson et al. (2001) it will turn out that for a given ad valorem tax, $\tau$, the equivalent specific tax that results in the same price is: $t=\tau \kappa$. After the government sets the ad valorem or specific tax, the Cournot oligopoly stage game is played an infinite number of times by the firms with profits discounted by the discount factor: $\delta$, where $0<\delta<1$.

When the other $n-1$ firms each produce: $q_{j}$, the profits of the $i$ th firm with an $a d$ valorem tax and with a specific tax are, respectively:

$$
\begin{aligned}
\pi_{i}^{\tau}\left(q_{i}, q_{j}\right) & =\frac{P\left(q_{i}+(n-1) q_{j}\right)}{1+\tau} q_{i}-\kappa q_{i} \\
\pi_{i}^{t}\left(q_{i}, q_{j}\right) & =P\left(q_{i}+(n-1) q_{j}\right) q_{i}-\kappa q_{i}-t q_{i}
\end{aligned}
$$

Following Anderson et al. (2001), if the specific tax is set equal to $t=\kappa \tau$ then the profits of the $i$ th firm with a specific tax are equal to its profits with an advalorem tax multiplied by $(1+\tau)$ :

\footnotetext{
3 The assumption of constant marginal cost is consistent with the assumption of Colombo and Labrecciosa (2013) that the cost function is convex, and with the assumption of Delipalla and Keen (1992) that the Seade (1980) stability condition is satisfied. Constant marginal cost is a fairly standard assumption in oligopoly models especially in the analysis of collusion.

4 This is the standard assumption about the timing of tax setting in the analysis of taxation under oligopoly. Note that in Colombo and Labrecciosa (2013) and Delipalla and Keen (1992) the ad valorem tax is expressed as a proportion of the consumer price, but this does not alter the results of the analysis.
} 


$$
\pi_{i}^{t}\left(q_{i}, q_{j}\right)=(1+\tau)\left[\frac{P\left(q_{i}+(n-1) q_{j}\right) q_{i}}{1+\tau}-\kappa q_{i}\right]=(1+\tau) \pi_{i}^{\tau}\left(q_{i}, q_{j}\right)
$$

Since the firms take the tax rates as exogenous constants, for a given $q_{j}^{*}$, if $q_{i}^{*}$ maximises $\pi_{i}^{t}\left(q_{i}, q_{j}^{*}\right)$ then it also maximises $\pi_{i}^{\tau}\left(q_{i}, q_{j}^{*}\right)$. This neat result of Anderson et al. (2001) turns out to be very useful in the analysis of taxation in the infinitely-repeated game.

In an infinitely-repeated game, the folk theorem implies that collusion can be sustained at the monopoly price if the discount factor is sufficiently high. As in Colombo and Labrecciosa (2013), the sustainability of collusion will be analysed for the case of Nash-reversion (grim trigger) strategies and for the case of optimal-punishment (stick and carrot) strategies.

\subsection{Nash-reversion strategies}

Collusion can be sustained at the monopoly price in this infinitely repeated game by the threat of reversion to the Nash equilibrium as in Friedman (1971). The strategy of each firm, in the collusive phase, is to produce the joint profit-maximising output as long as all the other firms have done so in all the previous periods. If a firm deviates from the collusive phase then, in the deviation phase, it will maximise its profits while all the other firms produce the collusive output for one period. Following any deviation, from the next period onwards, in the punishment phase, all firms will produce the Cournot-Nash outputs. In the collusive phase, the firms maximise joint profits, $\Pi=\sum_{j=1}^{n} \pi_{j}$, hence (2) implies that if $t=\kappa \tau$ then the joint profit-maximising output of each firm is the same with both taxes, $q_{M}$ and the collusive profits of each firm with a specific tax are $(1+\tau)$ times collusive profits with an ad valorem tax, $\pi^{t}\left(q_{M}\right)=(1+\tau) \pi^{\tau}\left(q_{M}\right)$. In the deviation phase, while the other $n-1$ firms each produce the collusive output $q_{M}$, the deviating $i$ th firm maximises profits (1) and, when $t=\kappa \tau$, (2) implies that the profit-maximising output when a firm deviates from collusion is the same with both taxes, $q_{D}$, and the profits of the deviating firm in the deviation phase of the game with a specific tax are $(1+\tau)$ times the profits with the ad valorem tax $\pi_{D}^{t}\left(q_{M}\right)=(1+\tau) \pi_{D}^{\tau}\left(q_{M}\right)$. In the punishment phase, there is a symmetric Cournot equilibrium where all firms maximise profits (1) and, when $t=\kappa \tau,(2)$ implies that Cournot-equilibrium output will be the same with both taxes, $q_{N}$, and the profits of each firm in the punishment phase of the game (the Cournot equilibrium) with specific tax are $(1+\tau)$ times the profits with the ad valorem tax: $\pi^{t}\left(q_{N}\right)=(1+\tau) \pi^{\tau}\left(q_{N}\right)$.

Collusion can be sustained by Nash-reversion strategies if the discounted present value of profits in the collusive phase exceeds the discounted present value of profits from deviation for one period followed by Cournot-Nash equilibrium profits in the punishment phase:

$$
\frac{1}{1-\delta} \pi^{z}\left(q_{M}\right) \geq \pi_{D}^{z}\left(q_{M}\right)+\frac{\delta}{1-\delta} \pi^{z}\left(q_{N}\right) \quad z=\tau, t
$$


Collusion is sustainable if the discount factor is greater than the critical value defined when (3) holds with equality. Hence, the critical discount factors with an ad valorem tax and with a specific tax are:

$$
\delta^{\tau}=\frac{\pi_{D}^{z}\left(q_{M}\right)-\pi^{z}\left(q_{M}\right)}{\pi_{D}^{z}\left(q_{M}\right)-\pi^{z}\left(q_{N}\right)} \quad z=\tau, t
$$

When $t=\tau \kappa$, profits with the specific tax are $(1+\tau)$ times the profits with the $a d$ valorem tax in each phase of the game. Hence, the critical discount factor required to sustain collusion is the same with both taxes, $\delta^{\tau}=\delta^{t}$. This leads to the following proposition:

Proposition 1 In the Cournot oligopoly supergame with collusion being supported by Nash-reversion strategies the critical discount factor is the same with an ad valorem tax as with a specific tax that results in the same price in the collusive phase.

If both taxes lead to the same price in the collusive phase then the critical discount factor is the same with both taxes..$^{5}$ The intuition for this result is that although the two taxes have different effects on profits, they both have the same effect on the relative profitability of collusion, deviation and punishment. Since relative profitability is unaffected by the form of taxation, the discount factor is the same with both taxes. This result contrasts with Proposition 1 of Colombo and Labrecciosa (2013), where a shift from a specific to an ad valorem tax leads to a strict reduction in the critical discount factor.

In the collusive phase of the game, when $t=\kappa \tau$, since outputs and price with the specific tax are the same as outputs and price with the ad valorem tax, it follows that consumer surplus and welfare will be the same with both taxes, but tax revenue is higher and profits are lower with the ad valorem tax than with the specific tax.

\subsection{Optimal punishments}

Collusion can be sustained at the monopoly price in this infinitely repeated game by the use of optimal symmetric punishments as in Abreu (1986), where the punishment lasts for one period and then the firms revert to collusion. The strategy of each firm, in the collusive phase, is to produce the collusive output provided there has been no deviation in the previous stage. Following a deviation, each firm will produce punishment output for one period, the punishment phase, and then revert to the collusive phase if all firms went along with the punishment. If a firm deviates from the punishment phase, then the punishment phase will continue for another period. In the collusive phase, when $t=\kappa \tau$ the joint profit-maximising output of each firm will be the same with both taxes and is given by $q_{M}$. Similarly, the output of a firm when it deviates from the collusive phase will be the same with both taxes if $t=\tau \kappa$, and is given by $q_{D}$.

\footnotetext{
5 Note that if both taxes lead to the same price in the collusive phase then prices with the two taxes will be the same in the deviation phase, and prices with the two taxes will be the same in the punishment phase.
} 
In the punishment phase, suppose that each firm produces output $q_{P}$, which is assumed to be the same with both taxes when $t=\tau \kappa$. Later, it will be verified that this assumption is justified. The profits of each firm in the punishment phase with the specific tax are $1+\tau$ times the profits with the ad valorem tax, $\pi^{t}\left(q_{P}\right)=$ $(1+\tau) \pi^{\tau}\left(q_{P}\right)$. If the $i$ th firm deviates from the punishment phase, while the other $n-1$ firms each produce the punishment output $q_{P}$, then the $i$ th firm maximises profits (1) and, when $t=\kappa \tau,(2)$ implies that the profit-maximising output is the same with both taxes, $q_{D P}$. The profits of the firm deviating from the punishment phase of the game with the specific tax are $(1+\tau)$ times the profits with the ad valorem tax: $\pi_{D}^{t}\left(q_{P}\right)=(1+\tau) \pi_{D}^{\tau}\left(q_{P}\right)$.

As in Abreu (1986), for the punishment to be credible, the gain from deviating in the punishment phase in any period is less than the present discounted value of the loss in the next period:

$$
\delta\left[\pi^{z}\left(q_{M}\right)-\pi^{z}\left(q_{P}\right)\right] \geq \pi_{D}^{z}\left(q_{P}\right)-\pi^{z}\left(q_{P}\right) \quad z=\tau, t
$$

The optimal punishment output is the largest output that solves (5) when it holds with equality. Since profits with the specific tax are $1+\tau$ times the profits with the $a d$ valorem tax when $t=\tau \kappa$, any solution for an ad valorem tax is also a solution for a specific tax. Therefore, as assumed above, the optimal punishment output is the same with both taxes.

It is also necessary that the firms find it profitable to continue with the supergame following any deviation from the collusive phase. The participation constraint of the firms requires that the discounted future profits from collusion must exceed any losses in the punishment phase: $\pi^{z}\left(q_{P}\right)+\delta \pi^{z}\left(q_{M}\right) /(1-\delta) \geq 0$. Since $c(0)=0$, a deviating firm can always produce zero output and make zero profits so $\pi_{D}^{z}\left(q_{P}\right) \geq 0$, and hence the credibility condition (5) implies that the participation constraint holds. ${ }^{6}$

For collusion to be sustainable, the gain from deviating in the collusive phase in any period is less than the present discounted value of the loss in the next period:

$$
\delta\left[\pi^{z}\left(q_{M}\right)-\pi^{z}\left(q_{P}\right)\right] \geq \pi_{D}^{z}\left(q_{M}\right)-\pi^{z}\left(q_{M}\right) \quad z=\tau, t
$$

Collusion is sustainable if the discount factor is greater than the critical value defined when (6) holds with equality. Hence, the critical discount factors with an ad valorem tax and with a specific tax are:

$$
\delta_{P}^{\tau}=\frac{\pi_{D}^{z}\left(q_{M}\right)-\pi^{z}\left(q_{M}\right)}{\pi^{z}\left(q_{M}\right)-\pi^{z}\left(q_{P}\right)} \quad z=\tau, t
$$

\footnotetext{
6 The participation constraint may or may not be binding. Colombo and Labrecciosa (2013) assume that the participation constraint binds in their analysis of optimal punishments. However, with linear demand and differentiated products, Lambertini and Sasaki (1999) show that the participation constraint will only bind at the critical discount factor in the case of Bertrand duopoly and perfect substitutes. In a homogeneous product Cournot duopoly with linear demand and constant marginal cost, the lowest discount factor at which the participation constraint binds is $\delta=8 / 9$ while collusion at the monopoly price can be sustained for discount factors above the critical discount factor: $\delta_{P}=9 / 32$, hence the participation constraint does not bind at the critical discount factor.
} 
When $t=\tau \kappa$, profits with the specific tax are $1+\tau$ times the profits with the $a d$ valorem tax in each phase of the game so the critical discount factor required to sustain collusion is the same with both taxes. This leads to the following proposition:

Proposition 2 In the Cournot oligopoly supergame with collusion being supported by optimal symmetric punishment strategies the critical discount factor is the same with an ad valorem tax as with a specific tax that results in the same price in the collusive phase.

The result with optimal punishment strategies is the same as with Nash-reversion strategies, and the intuition is also the same. ${ }^{7}$ The results in Propositons 1 and 2 contrast with Propositions 1 and 2 of Colombo and Labrecciosa (2013), where a shift from a specific to an ad valorem tax will lead to a strict reduction in the critical discount factor. The explanation for the different results is that their analysis uses the $P$-shift as in Delipalla and Keen (1992) rather than the approach used in Anderson et al. (2001). With the $P$-shift, the reduction in the specific tax and the increase in the ad valorem tax are such that the first-round effect (holding the price constant) on tax revenue is zero, that is $-d t=P d \tau /(1+\tau)^{2}>0$, which implies that the tax changes are proportional to the price in each phase of the infinitely-repeated game. Since the prices are different in each phase (collusive, deviation and punishment), the necessary tax changes will be different in each phase, and the tax rates in Colombo and Labrecciosa (2013) should really be conditional on the phase of the game. ${ }^{8}$ Therefore, using the $P$-shift to analyse taxation in an infinitely-repeated game does not seem to be valid approach, and it will not be used in the next section that considers the case of increasing marginal cost.

In the collusive phase of the game, when $t=\kappa \tau$, since outputs and price with the specific tax are the same as outputs and price with the ad valorem tax, it follows that the equilibrium price, consumer surplus and welfare will be the same with both taxes, but tax revenue is higher and profits are lower with the ad valorem tax than with the specific tax.

\section{Cournot duopoly with linear demand and quadratic costs}

In the previous section, the assumption of constant marginal cost allowed clear-cut results to be obtained with general demand functions using the approach of Anderson et al. (2001). This section will consider the case of increasing marginal cost but, as in most of the literature on collusion in infinitely-repeated games, this will require the use of particular functional forms so that explicit solutions can be obtained for outputs and profits. Also, this section will consider the possibility of partial collusion when full collusion cannot be sustained, which was not considered by Colombo and Labrecciosa (2013). Since there are infinitely many equilibria of the Cournot duopoly

\footnotetext{
7 It is straightforward to extend the analysis to the case of Bertrand oligopoly with differentiated products, see Azacis and Collie (2014).

8 When the taxes are conditional on the phase of the game then the government has to know in advance that a firm is going to deviate, and the tax set by the government will signal to the other firms that a firm is going to deviate, which would lead all firms to deviate. Therefore, conditional taxes are impossible to implement.
} 
supergame, it seems reasonable when comparing the two taxes to compare the most profitable equilibria that can be sustained for a given discount rate. This is especially true when comparing the tax revenue raised by the two taxes.

Consider an infinitely-repeated Cournot duopoly, $n=2$, where firms produce a homogeneous product, and the firms have identical quadratic cost functions. ${ }^{9}$ The $i$ th firm has the cost function: $c\left(q_{i}\right)=\kappa q_{i}+\theta q_{i}^{2} / 2$, where $\kappa \geq 0$ and $\theta \geq 0$, and hence its marginal cost is $c^{\prime}\left(q_{i}\right)=\kappa+\theta q_{i} \geq 0$, which is increasing in output if $\theta>0$ and constant if $\theta=0$. The inverse demand function is linear: $P(Q)=\alpha-\beta\left(q_{1}+q_{2}\right)$, where $\alpha>(1+\tau)(\kappa+t) \geq 0$ and $\beta>0 .{ }^{10}$ It is useful to define the variable $\mu \equiv$ $\theta / \beta \geq 0$, which is the slope of a firm's marginal cost curve relative to the slope of the demand function, and is equal to zero in the case of constant marginal cost. Also, to simplify the expressions later in the paper, it is useful to define the following terms: $A \equiv \alpha-(1+\tau)(\kappa+t)>0, B_{I} \equiv I+\mu(1+\tau)>0$, where $I=1,2, \ldots, 6$, $D_{1} \equiv(3+\mu)^{2}-\delta(5+2 \mu)>0$ and $D_{2} \equiv(3+\mu)^{2}-4(2+\mu) \delta>0$. Note that only $A$ is a function of the specific tax, $t$, while $D_{1}$ and $D_{2}$ do not depend upon either the ad valorem or the specific tax. With these demand and cost functions, the profits of the- $i$ th firm when its competitor produces output $q_{j}$, given the ad valorem and specific taxes, are:

$$
\pi_{i}=\frac{P\left(q_{i}+q_{j}\right)}{1+\tau} q_{i}-c\left(q_{i}\right)-t q_{i}=\frac{\alpha-\beta\left(q_{i}+q_{j}\right)}{1+\tau} q_{i}-\kappa q_{i}-\theta \frac{q_{i}^{2}}{2}-t q_{i}
$$

It is straightforward to solve for the joint profit-maximising output and profits of each firm as functions of the two taxes:

$$
q_{M}=\frac{A}{\beta B_{4}}, \quad \pi\left(q_{M}\right)=\frac{A^{2}}{2 \beta(1+\tau) B_{4}}
$$

The solutions for an ad valorem tax are derived by setting the specific tax equal to zero, $t=0$, and are denoted by a superscript $\tau$. Similarly, the solutions for a specific tax are derived by setting the ad valorem tax equal to zero, $\tau=0$, and are denoted by a superscript $t$. For example, the joint profit-maximising output is $q_{M}^{\tau}=$ $(\alpha-\kappa-\tau \kappa) /\left(\beta B_{4}\right)$ with an ad valorem tax and is $q_{M}^{t}=(\alpha-\kappa-t) /(\beta(4+\mu))$ with a specific tax.

\subsection{Nash-reversion strategies}

When the discount factor is less than the critical value, it is not possible to sustain collusion at the joint profit-maximising price, but partial collusion at a lower price may still be possible using Nash-reversion strategies. To find the maximum level of

\footnotetext{
9 Rothschild (1999) considers collusion in a model with linear demand and quadratic costs, but with asymmetric firms, and he does not consider the effects of taxes. Dierickx et al. (1988) also use quadratic cost functions, but they do not analyse collusion.

10 It is assumed that marginal cost is sufficiently high so that the price is always positive even during the punishment phase of the game.
} 
collusion that can be sustained for a given discount factor, let $q_{C}$ be the collusive output. Then, the profits of the firms from colluding are:

$$
\pi\left(q_{C}\right)=\frac{q_{C}\left(2 A-\beta B_{4} q_{C}\right)}{2(1+\tau)}
$$

If the other firm produces output $q_{C}$ then the profit-maximising output and profits for a firm that deviates are:

$$
q_{D}\left(q_{C}\right)=\frac{A-\beta q_{C}}{\beta B_{2}}, \quad \pi_{D}\left(q_{C}\right)=\frac{\left(A-\beta q_{C}\right)^{2}}{2 \beta(1+\tau) B_{2}}
$$

Following a deviation by either firm, in the punishment phase, both firms will produce the Cournot-Nash output forever thereafter. It is straightforward to show that the Cournot-Nash equilibrium output and profits are:

$$
q_{N}=\frac{A}{\beta B_{3}}, \quad \pi\left(q_{N}\right)=\frac{A^{2} B_{2}}{2 \beta(1+\tau) B_{3}^{2}}
$$

The lowest collusive output that can be sustained using Nash-reversion trigger strategies for any given discount factor can be obtained by solving:

$$
\delta=\frac{\pi_{D}\left(q_{C}\right)-\pi\left(q_{C}\right)}{\pi_{D}\left(q_{C}\right)-\pi\left(q_{N}\right)}
$$

Using (10), (11) and (12) to solve (13) for the collusive output as a function of the discount factor yields:

$$
q_{C}(\delta)=\frac{A\left(B_{3}^{2}-\delta\left(B_{2}+B_{3}\right)\right)}{\beta B_{3}\left(B_{3}^{2}-\delta\right)}
$$

The collusive output is decreasing in the discount factor and is equal to the CournotNash output when $\delta=0$. Full collusion at the joint profit-maximising price can be sustained if the discount factor is greater than some critical value, and this critical value can be found by solving $q_{C}(\delta)=q_{M}$, which yields the critical discount factor: $\delta_{N}=B_{3}^{2} /\left(17+2 \mu(1+\tau) B_{6}\right)$. Note that with constant marginal cost, $\mu=0$, the critical discount factor is: $\delta_{N}=9 / 17$, which does not depend upon the tax rates. With increasing marginal cost, setting $t=0$ yields the critical discount factor with an $a d$ valorem tax and setting $\tau=0$ yields the critical discount factor with a specific tax, respectively:

$$
\delta_{N}^{\tau}=\frac{B_{3}^{2}}{17+2 \mu(1+\tau) B_{6}}, \quad \delta_{N}^{t}=\frac{(3+\mu)^{2}}{17+2 \mu(6+\mu)}>\delta_{N}^{\tau}
$$

As shown in Fig. 1, the critical discount factor with the specific tax does not depend upon the tax rate, and is higher than the critical discount with the ad valorem tax. 


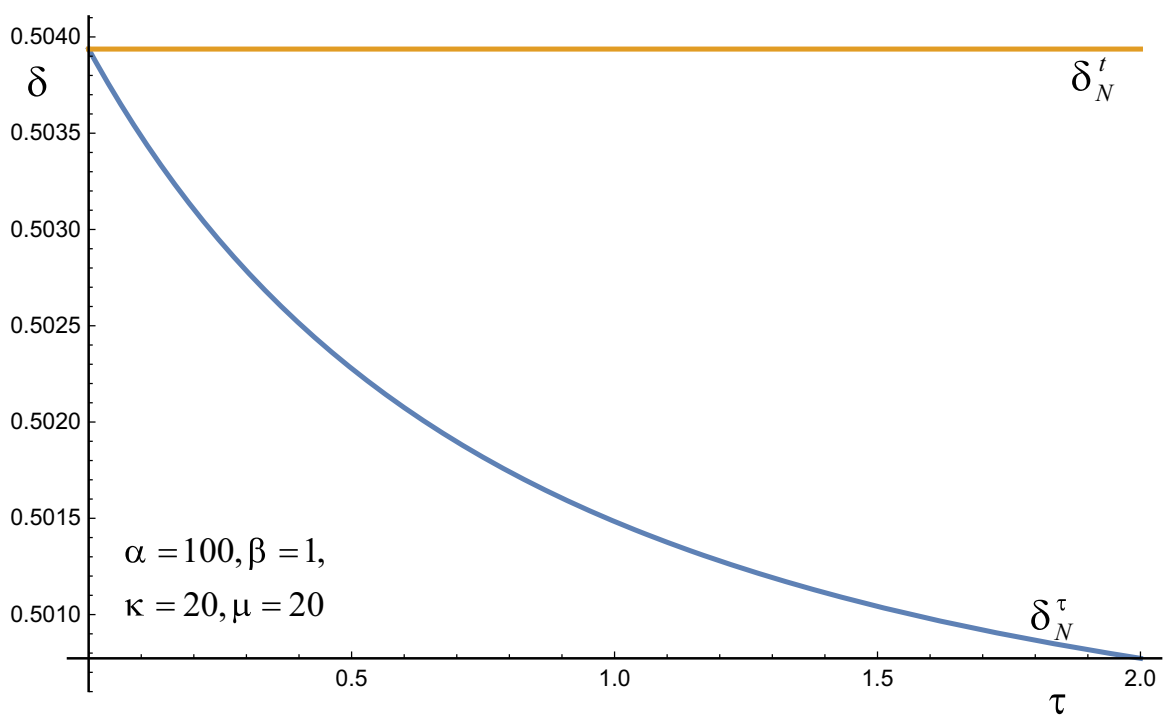

Fig. 1 Nash-reversion discount factors with linear demand

Therefore, there is a range of values for the discount factor, $\delta \in\left[\delta_{N}^{\tau}, \delta_{N}^{t}\right]$, where full collusion can be sustained with an ad valorem tax, but cannot be sustained with a specific tax. In this range of values for the discount factor, Colombo and Labrecciosa (2013) claim that tax revenue may be higher with a specific tax than that with an valorem tax that yields the same price. However, they assume that if full collusion is not possible then the result will be the Cournot-Nash equilibrium even though partial collusion can still be sustained with a specific tax, and obviously partial collusion is preferred by the firms. If instead one allows for the possibility of partial collusion with a specific tax then for $\delta \in\left[\delta_{N}^{\tau}, \delta_{N}^{t}\right]$ there will be full collusion with an ad valorem tax but partial collusion with a specific tax. The specific tax can be set so that the price will be the same as with the ad valorem tax so $q_{M}^{\tau}=q_{C}^{t}(\delta)$. Since both taxes lead to the same price and output, tax revenue will be higher with an ad valorem tax than with a specific tax if the difference in revenue per unit, $\Delta R_{N}=\tau P_{M}^{\tau} /(1+\tau)-t$, is positive. When $\delta \in\left[0, \delta_{N}^{\tau}\right]$ there will be partial collusion with both taxes and if the specific tax is set so that $q_{C}^{\tau}(\delta)=q_{C}^{t}(\delta)$ then $\Delta R_{N}=\tau P_{C}^{\tau} /(1+\tau)-t$. When $\delta \in\left[\delta_{N}^{t}, 1\right]$ there will be full collusion with both taxes and if the specific tax is set so that $q_{M}^{\tau}=q_{M}^{t}$ then $\Delta R_{N}=\tau P_{M}^{\tau} /(1+\tau)-t$. Allowing for all three possibilities, it can be shown that the difference in revenue per unit is:

$$
\Delta R_{N}=\left\{\begin{array}{lc}
\frac{\tau(\alpha-(1+\tau) \kappa) E}{(1+\tau) B_{3}\left(B_{3}^{2}-\delta\right) D_{1}}>0 & 0 \leq \delta \leq \delta_{N}^{\tau} \\
\frac{(\alpha-(1+\tau) \kappa) F}{(1+\tau) B_{4} D_{1}}>0 & \delta_{N}^{\tau}<\delta \leq \delta_{N}^{t} \\
\frac{2 \tau(\alpha-(1+\tau) \kappa)}{(1+\tau) B_{4}}>0 & \delta_{N}^{t}<\delta \leq 1
\end{array}\right.
$$




$$
\begin{aligned}
E= & (3+\mu)^{2} B_{3}^{2}-\left(35+14(2+\tau) \mu+6(1+\tau) \mu^{2}\right) \delta^{2} \\
& +\left(2(1+\mu)^{2}(3+\mu)^{2}+4 \mu(1+\mu)(2+\mu)(3+\mu) \tau+\mu^{2}\left(7+8 \mu+2 \mu^{2}\right) \tau^{2}\right) \delta \\
F= & \left(17+7 \mu+(12+8 \mu) \tau+2(1+\tau) \mu^{2}\right) \delta-(3+\mu)^{2}(1-\tau)
\end{aligned}
$$

The only terms where the sign is not immediately clear are $E$ and $F$, but these terms can be signed quite easily. Since the term $E$ is a concave quadratic in the discount factor, which is positive when $\delta=0$ and when $\delta=\delta_{N}^{\tau}$, it will be positive for $\delta \in\left[0, \delta_{N}^{\tau}\right]$. Since the term $F$ is positive when $\delta=\delta_{N}^{\tau}$ and it is increasing in the discount factor, it will be positive for $\delta \in\left[\delta_{N}^{\tau}, \delta_{N}^{t}\right]$. Therefore, an ad valorem tax yields a higher revenue than a specific tax that results in the same price in the collusive phase. ${ }^{11}$ This leads to the following proposition:

Proposition 3 In the Cournot duopoly supergame with linear demand and quadratic costs where collusion is supported by Nash-reversion trigger strategies, tax revenue is higher with an ad valorem tax than with a specific tax that results in the same price in the collusive phase.

It is known that an ad valorem tax yields higher tax revenue than a specific tax under full collusion, when $\delta \geq \delta_{N}^{t}$, as this is equivalent to monopoly, and under Cournot oligopoly, when $\delta=0$. When there is full collusion with an ad valorem tax and partial collusion with a specific tax, to keep the collusive price the same with the two taxes the specific tax will have to increase (compared to full collusion) thereby increasing tax revenue with the specific tax. However, Proposition 3 has shown that this increase in tax revenue is not sufficient to overcome the inherent superiority of an ad valorem tax under oligopoly. ${ }^{12}$ Allowing partial collusion when the discount factor is lower than the critical value, a possibility not considered by Colombo and Labrecciosa (2013), restores the conventional wisdom that an ad valorem tax yields higher revenue than a specific tax that results in the same price.

\subsection{Optimal punishment strategies}

Partial collusion can also be sustained using optimal symmetric punishment strategies as in Abreu (1986). The profits in the collusive phase when each firm produces output $q_{C}$ are given by (10), and the profits if a firm deviates from the collusive phase are given by (11). Similarly, in the punishment phase, the profits when each firm produces output $q_{P}$ are:

$$
\pi\left(q_{P}\right)=\frac{q_{P}\left(2 A-\beta B_{4} q_{P}\right)}{2(1+\tau)}
$$

\footnotetext{
11 Some readers may find it paradoxical that an ad valorem tax is superior to a specific tax when there is full collusion with the ad valorem tax but only partial collusion with the specific tax. However, both taxes result in the same consumer price and hence there is no difference between the two taxes for consumers. Also, partial collusion may only be slightly more competitive than full collusion.

12 Given that there are these two opposing effects, it is difficult to generalise Proposition 3 although one may suspect that it is a fairly general result.
} 
The output and profits when a firm deviates from the punishment phase and the other firm produces the collusive output $q_{P}$ are:

$$
q_{D}\left(q_{P}\right)=\frac{A-\beta q_{P}}{\beta B_{2}}, \quad \pi_{D}\left(q_{P}\right)=\frac{\left(A-\beta q_{P}\right)^{2}}{2 \beta(1+\tau) B_{2}}
$$

With partial collusion, the outputs in the collusive and the punishment phases are obtained by solving the credibility and sustainability conditions for a given discount factor, as in Abreu (1986):

$$
\begin{aligned}
& \pi_{D}\left(q_{P}\right)-\pi\left(q_{P}\right)=\delta\left[\pi\left(q_{C}\right)-\pi\left(q_{P}\right)\right] \\
& \pi_{D}\left(q_{C}\right)-\pi\left(q_{C}\right)=\delta\left[\pi\left(q_{C}\right)-\pi\left(q_{P}\right)\right]
\end{aligned}
$$

Solving for the outputs in the collusive and punishment phases as functions of the discount factor, and ignoring the trivial solution where both the outputs are equal to the Cournot-Nash equilibrium outputs, $q_{C}=q_{P}=q_{N}$, yields:

$$
q_{C}(\delta)=\frac{A}{\beta B_{3}^{3}}\left(B_{3}^{2}-4 \delta B_{2}\right), \quad q_{P}(\delta)=\frac{A}{\beta B_{3}^{3}}\left(B_{3}^{2}+4 \delta B_{2}\right)
$$

Both outputs are linear in the discount factor with the collusive output decreasing in $\delta$ and the punishment output increasing in $\delta$, and both are equal to the CournotNash output when $\delta=0$. Full collusion at the joint profit-maximising price can be sustained if the discount factor is greater than some critical value, and this critical value can be obtained by solving $q_{C}(\delta)=q_{M}$, which yields the critical discount factor: $\delta_{P}=B_{3}^{2} /\left(4 B_{2} B_{4}\right)$. Note that with constant marginal cost, $\mu=0$, the critical discount factor is: $\delta_{P}=9 / 32$, which does not depend upon the tax rates. With increasing marginal cost, setting $t=0$ yields the critical discount factor with an ad valorem tax and setting $\tau=0$ yields the critical discount factor with a specific tax, respectively:

$$
\delta_{P}^{\tau}=\frac{B_{3}^{2}}{4 B_{2} B_{4}}, \quad \delta_{P}^{t}=\frac{(3+\mu)^{2}}{4(2+\mu)(4+\mu)}>\delta_{P}^{\tau}
$$

As shown in Fig. 2, the critical discount factor with the specific tax does not depend upon the tax rate, whereas the critical discount with the ad valorem tax is decreasing in the tax rate, $\partial \delta_{P}^{\tau} / \partial \tau<0$, and they are equal when there are no taxes, $t=\tau=0$. Therefore, there is a range of values for the discount factor, $\delta \in\left[\delta_{P}^{\tau}, \delta_{P}^{t}\right]$, where full collusion can be sustained with an ad valorem tax, but cannot be sustained with a specific tax. However, partial collusion can be sustained with a specific tax.

As in the case of Nash-reversion strategies, the specific tax can be set so that the price in the collusive phase is the same as with the ad valorem tax. Since both taxes lead to the same output, and again allowing for all three possibilities, the difference in revenue per unit with the ad valorem and specific tax can be shown to be: 


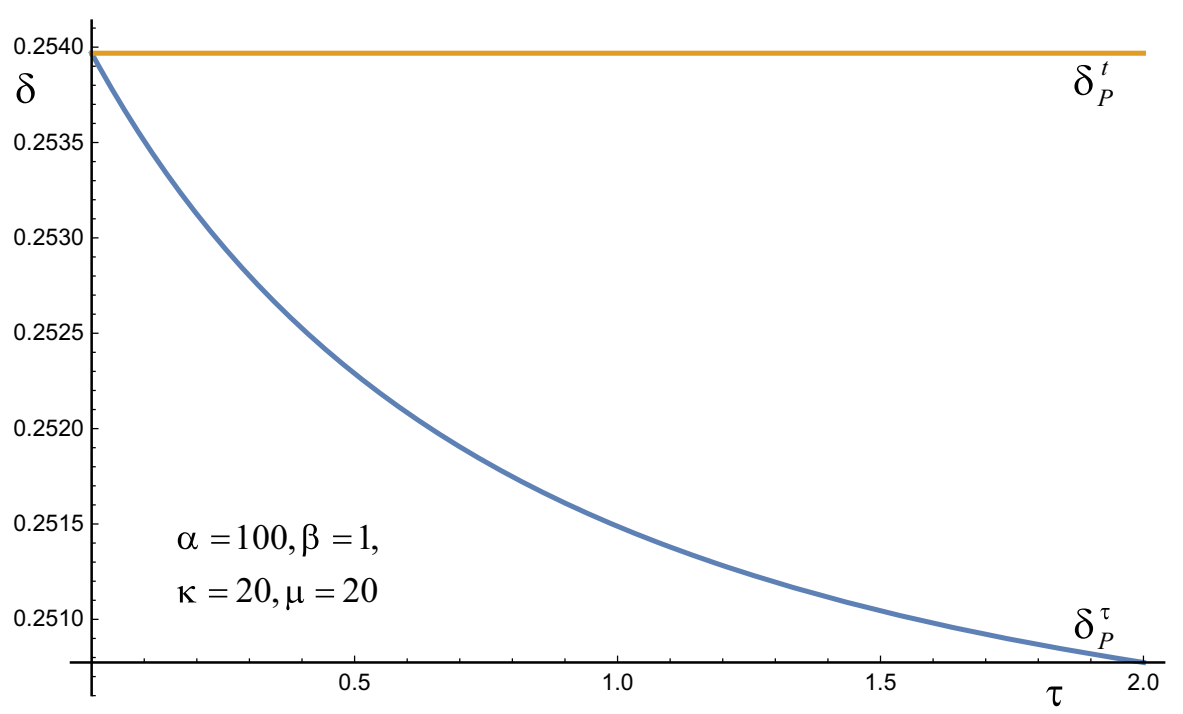

Fig. 2 Optimal-punishment discount factors with linear demand

$$
\Delta R_{P}= \begin{cases}\frac{\tau(\alpha-(1+\tau) \kappa) G}{(1+\tau) B_{3}^{3} D_{2}}>0 & 0 \leq \delta \leq \delta_{P}^{\tau} \\ \frac{(\alpha-(1+\tau) \kappa) H}{(1+\tau) B_{4} D_{2}}>0 & \delta_{P}^{\tau}<\delta \leq \delta_{P}^{t} \\ \frac{2 \tau(\alpha-(1+\tau) \kappa)}{(1+\tau) B_{4}}>0 & \delta_{P}^{t}<\delta \leq 1\end{cases}
$$

$$
\begin{aligned}
G= & (3+\mu)^{2} B_{3}^{2}-32(2+\mu) B_{2} \delta^{2} \\
& +4\left((3+\mu)^{2}\left(2+2 \mu+\mu^{2}\right)+\mu(3+\mu)\left(5+6 \mu+2 \mu^{2}\right) \tau+\mu^{2}(2+\mu)^{2} \tau^{2}\right) \delta \\
H= & 4(2+\mu)\left(B_{4}+2 \tau\right) \delta-(3+\mu)^{2}(1-\tau)
\end{aligned}
$$

The only terms where the sign is not immediately clear are $G$ and $H$, but these terms can be signed quite easily. Since the term $G$ is a concave quadratic, which is positive when $\delta=0$ and when $\delta=\delta_{P}^{\tau}$, it will be positive for $\delta \in\left[0, \delta_{P}^{\tau}\right]$. Since the term $H$ is positive when $\delta=\delta_{P}^{\tau}$ and it is increasing in $\delta$, it will be positive for $\delta \in\left[\delta_{P}^{\tau}, \delta_{P}^{t}\right]$. Therefore, an ad valorem tax yields a higher revenue than a specific tax that results in the same price in the collusive phase. This leads to the following proposition:

Proposition 4 In the Cournot duopoly supergame with linear demand and quadratic costs where collusion is supported by optimal-punishment strategies, tax revenue is higher with an ad valorem tax than with a specific tax that results in the same price in the collusive phase.

Again, allowing partial collusion when the discount factor is lower than the critical value, restores the conventional wisdom that an ad valorem tax yields higher revenue 


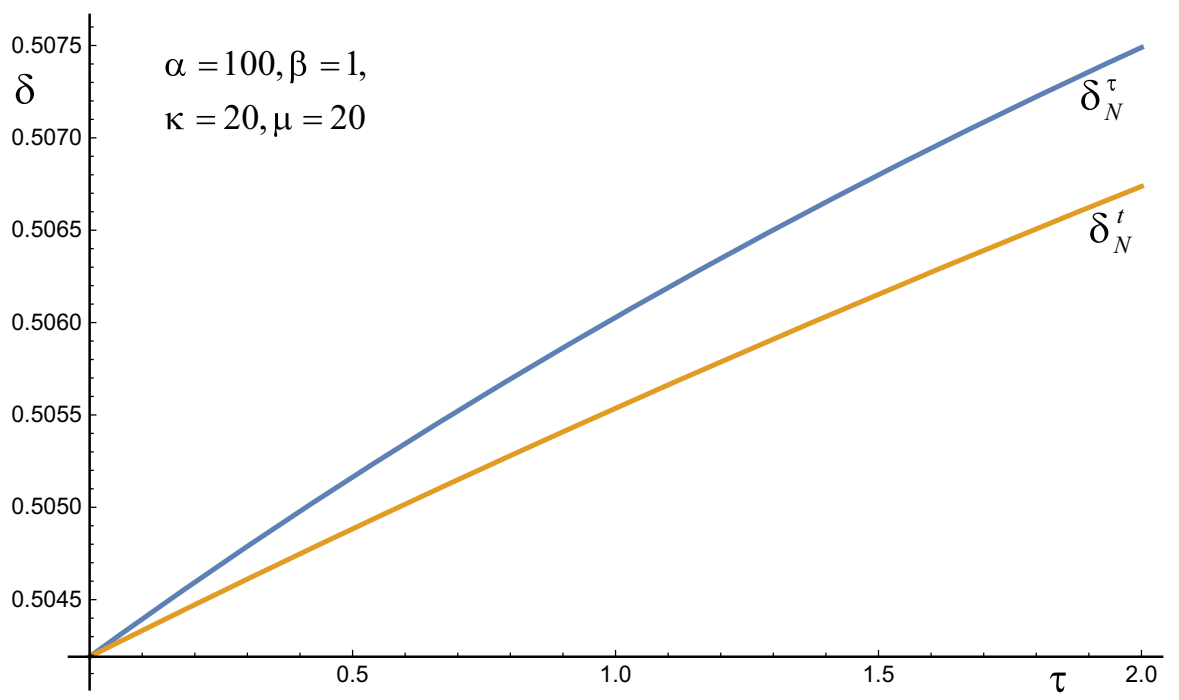

Fig. 3 Nash-reversion discount factors with quadratic demand

than a specific tax that results in the same price, in contrast to Proposition 3 of Colombo and Labrecciosa (2013).

With this linear demand function (and quadratic costs), the critical discount factor for full collusion was higher with a specific tax than with an ad valorem tax for the case of Nash-reversion punishments and for the case of optimal punishments, which is in line with the results of Colombo and Labrecciosa (2013) that it is easier to sustain collusion with an ad valorem tax than with a specific tax. A counterexample can be used to show that this is not a general result. If the inverse demand function is changed to be: $P=\left(\alpha-\beta\left(q_{1}+q_{2}\right)\right)^{2}$, and the cost function is the same as above then the model can be solved explicitly for the case of Nash-reversion punishments using the same steps as in Sect. 3.1. ${ }^{13}$ Figure 3 shows the critical discount factors as a function of the ad valorem tax rate, and it can be seen that the critical discount factor is higher with an ad valorem tax than with a specific tax. In this counter-example, it is easier to sustain collusion with a specific tax than with an ad valorem tax. However, it will still be the case that tax revenue is always higher with an ad valorem tax than with a specific tax. When the discount factor is such that full collusion is sustainable with a specific tax but only partial collusion is sustainable with an ad valorem tax, the specific tax would have to be reduced (compared to under full collusion) to keep the collusive price the same with the two taxes, which would reduce tax revenue with the specific tax, which would strengthen the superiority of the ad valorem tax.

13 This demand function is a special case of the demand function used by Lambertini (1996) to analyse collusion, which was first suggested in a different context by Anderson and Engers (1992). 


\section{Conclusions}

The analysis has compared the effects of ad valorem and specific taxes that result in the same price on the sustainability of collusion in infinitely repeated oligopoly models. Assuming constant marginal cost, it was shown that a switch from specific to ad valorem taxation has no effect on the critical discount factor required to sustain collusion. This result was shown to hold for Cournot oligopoly with homogeneous products and general demand functions. It can also be shown for Bertrand oligopoly with differentiated products and general demand functions when collusion is sustained with Nash-reversion strategies or optimal-punishment strategies. The intuition for these results is that, although both taxes have different effects on profits, they have the same effect on relative profits because profits with an ad valorem tax are always proportional to profits with a specific tax. These results contrast with those of Colombo and Labrecciosa (2013) who use the $P$-shift of Delipalla and Keen (1992) in their analysis.

Also, in a Cournot duopoly model with linear demand and quadratic costs, it was shown that the critical discount factor was lower with an ad valorem tax than with a specific tax when marginal cost was increasing. In this case, there is a range of values for the discount factor where full collusion is possible with an ad valorem tax, but is not possible with a specific tax. In this region, in contrast to conventional wisdom, Colombo and Labrecciosa (2013) show that revenue may be higher with a specific tax than with an ad valorem tax, but they assume that the outcome will be Nash (Cournot or Bertrand) equilibrium if the discount factor is lower than the critical value. However, partial collusion is still possible when the discount factor is lower than the critical value. Allowing for the possibility of partial collusion, it was shown that revenue is always higher with an ad valorem tax than with a specific tax. Therefore, conventional wisdom still holds if the possibility of partial collusion is allowed in the comparison of the tax revenue from the two taxes.

Finally, a counterexample to the result of Colombo and Labrecciosa (2013) shows that it is possible that collusion is easier with a specific tax than with an advalorem tax. This counterexample demonstrates the difficulty of obtaining general results in infinitely-repeated games.

Acknowledgements We would like to thank the editor and referees for their detailed and constructive comments on an earlier version of this paper. We would also like to thank participants at the Association of Public Economic Theory conference in Luxembourg in 2014 and the 5th Annual Lithuanian Conference on Economic Research. We are responsible for any remaining errors.

Open Access This article is distributed under the terms of the Creative Commons Attribution 4.0 International License (http://creativecommons.org/licenses/by/4.0/), which permits unrestricted use, distribution, and reproduction in any medium, provided you give appropriate credit to the original author(s) and the source, provide a link to the Creative Commons license, and indicate if changes were made.

\section{References}

Abreu D (1986) Extremal equilibria of oligopolistic supergames. J Econ Theory 39(1):191-225. https:// doi.org/10.1016/0022-0531(86)90025-6 
Anderson SP, de Palma A, Kreider B (2001) The efficiency of indirect taxes under imperfect competition. J Public Econ 81(2):231-251. https://doi.org/10.1016/S0047-2727(00)00085-2

Anderson SP, Engers M (1992) Stackelberg versus Cournot oligopoly equilibrium. Int J Ind Organ 10(1):127-135. https://doi.org/10.1016/0167-7187(92)90052-Z

Azacis, H, Collie, DR (2014) Collusion and the sustainability of collusion: ad valorem versus specific taxes. In: Cardiff Economics Working Paper E2014/15

Colombo L, Labrecciosa P (2013) How should commodities be taxed? A supergame-theoretic analysis. J Public Econ 97:196-205. https://doi.org/10.1016/j.jpubeco.2012.08.001

Delipalla S, Keen M (1992) The comparison between ad valorem and specific taxation under imperfect competition. J Public Econ 49(3):351-367. https://doi.org/10.1016/0047-2727(92)90073-O

Dierickx I, Matutes C, Neven D (1988) Indirect taxation and cournot equilibrium. Int J Ind Organ 6(3):385399. https://doi.org/10.1016/S0167-7187(88)80019-5

Friedman JW (1971) A non-cooperative equilibrium for supergames. Rev Econ Stud 38(1):1-12. https:// doi.org/10.2307/2296617

Grazzini L (2006) A note on ad valorem and per unit taxation in an oligopoly model. J Econ 89(1):59-74. https://doi.org/10.1007/s00712-006-0201-y

Keen M (1998) The balance between specific and ad valorem taxation. Fisc Stud 19(1):1-37. https://doi. org/10.1111/j.1475-5890.1998.tb00274.x

Kolstad CD, Mathiesen L (1987) Necessary and sufficient conditions for uniqueness of a Cournot equilibrium. Rev Econ Stud 54(4):681-690. https://doi.org/10.2307/2297489

Kowalczyk C, Skeath SE (1994) Pareto ranking optimal tariffs under foreign monopoly. Econ Lett 45(3):355-359. https://doi.org/10.1016/0165-1765(94)90037-X

Lambertini L (1996) Cartel stability and the curvature of market demand. Bull Econ Res 48(4):329-335. https://doi.org/10.1111/j.1467-8586.1996.tb00639.x

Lambertini L, Sasaki D (1999) Optimal punishments in linear duopoly supergames with product differentiation. J Econ 69(2):173-188. https://doi.org/10.1007/BF01232420

McManus M (1962) Numbers and size in Cournot oligopoly. Bull Econ Res 14(1):14-22. https://doi.org/ 10.1111/j.1467-8586.1962.tb00310.x

McManus M (1964) Equilibrium, numbers and size in Cournot oligopoly. Bull Econ Res 16(2):68-75. https://doi.org/10.1111/j.1467-8586.1964.tb00517.x

Rothschild R (1999) Cartel stability when costs are heterogeneous. Int J Ind Organ 17(5):717-734. https:// doi.org/10.1016/S0167-7187(97)00052-0

Schröder PJH (2004) The comparison between ad valorem and unit taxes under monopolistic competition. J Econ 83(3):281-292. https://doi.org/10.1007/s00712-004-0096-y

Seade J (1980) On the effects of entry. Econometrica 48(2):479-489. https://doi.org/10.2307/1911111

Skeath SE, Trandel GA (1994a) A Pareto comparison of ad valorem and unit taxes in noncompetitive environments. J Public Econ 53(1):53-71. https://doi.org/10.1016/0047-2727(94)90013-2

Skeath S, Trandel GA (1994b) Pareto-superior trade policy. J Int Trade Econ Dev 3(3):277-288. https:// doi.org/10.1080/09638199400000018

Suits DB, Musgrave RA (1953) Ad valorem and unit taxes compared. Q J Econ 67(4):598-604. https://doi. org/10.2307/1883604

Vetter H (2013) Consumption taxes in monopolistic competition: a comment. J Econ 110(3):287-295. https://doi.org/10.1007/s00712-012-0320-6

Vetter H (2017) Commodity taxes and welfare under endogenous market conduct. J Econ. https://doi.org/ $10.1007 / \mathrm{s} 00712-017-0538-4$

Wang XH, Zhao J (2009) On the efficiency of indirect taxes in differentiated oligopolies with asymmetric costs. J Econ 96(3):223-239. https://doi.org/10.1007/s00712-008-0046-7 